\title{
Simulation-enhanced nurse mentoring to improve preeclampsia and eclampsia care: an education intervention study in Bihar, India
}

Julia H. Raney ${ }^{1 *}$ D, Melissa C. Morgann ${ }^{2,3}$, Amelia Christmas ${ }^{4}$, Mona Sterling $^{5}$, Hilary Spindler ${ }^{5}$, Rakesh Ghosh ${ }^{5}$, Aboli Gore ${ }^{6}$, Tanmay Mahapatra ${ }^{6}$ and Dilys M. Walker ${ }^{5,7}$

\begin{abstract}
Background: Inadequately treated, preeclampsia and eclampsia (PE/E) may rapidly lead to severe complications in both mothers and neonates, and are estimated to cause 60,000 global maternal deaths annually. Simulation-based training on obstetric and neonatal emergency management has demonstrated promising results in low- and middle-income countries. However, the impact of simulation training on use of evidence-based practices for PE/E diagnosis and management in low-resource settings remains unknown.

Methods: This study was based on a statewide, high fidelity in-situ simulation training program developed by PRONTO International and implemented in collaboration with CARE India on PE/E management in Bihar, India. Using a mixed methods approach, we evaluated changes over time in nurse mentees' use of evidence-based practices during simulated births at primary health clinics. We compared the proportion and efficiency of evidencebased practices completed during nurse mentees' first and last participation in simulated PE/E cases. Twelve semistructured interviews with nurse mentors explored barriers and enablers to high quality PE/E care in Bihar.

Results: A total of 39 matched first and last simulation videos, paired by facility, were analyzed. Videos occurred a median of 62 days apart and included 94 nurses from 33 primary health centers. Results showed significant increases in the median number of 'key history questions asked,' (1.0 to 2.0, $p=0.03$ ) and 'key management steps completed,' (2.0 to 3.0, $p=0.03$ ). The time from BP measured to magnesium sulfate given trended downwards by $3.2 \mathrm{~min}$, though not significantly $(p=0.06)$. Key barriers to high quality PE/E care included knowledge gaps, resource shortages, staff hierarchy between physicians and nurses, and poor relationships with patients. Enablers included case-based and simulation learning, promotion of teamwork and communication, and effective leadership.

Conclusion: Simulation training improved the use of evidence-based practices in PE/E simulated cases and has the potential to increase nurse competency in diagnosing and managing complex maternal complications such as PE/E. However, knowledge gaps, resource limitations, and interpersonal barriers must be addressed in order to improve care. Teamwork, communication, and leadership are key mechanisms to facilitate high quality PE/E care in Bihar.
\end{abstract}

Keywords: Preeclampsia, Eclampsia, Simulation, Barriers, Enablers, India

\footnotetext{
* Correspondence: Julia.Raney@yale.edu

${ }^{1}$ Yale School of Medicine, Yale University, 333 Cedar St, New Haven, CT

06510, USA

Full list of author information is available at the end of the article
}

(c) The Author(s). 2019 Open Access This article is distributed under the terms of the Creative Commons Attribution 4.0 International License (http://creativecommons.org/licenses/by/4.0/), which permits unrestricted use, distribution, and reproduction in any medium, provided you give appropriate credit to the original author(s) and the source, provide a link to the Creative Commons license, and indicate if changes were made. The Creative Commons Public Domain Dedication waiver (http://creativecommons.org/publicdomain/zero/1.0/) applies to the data made available in this article, unless otherwise stated. 


\section{Background}

Globally, an estimated 275,000 maternal deaths occurred in 2015 [1]. Hypertensive disorders of pregnancy, including preeclampsia and eclampsia (PE/E), are the second leading cause of maternal death in women under age 35 [1]. Mortality related to PE/E can be prevented with swift diagnosis, effective management, and timely delivery [2, 3]. However, evidence-based interventions are sparsely implemented in many low- and middle-income country settings, leading to poor outcomes for both mothers and neonates $[4,5]$.

In 2015, an estimated 64,000 maternal deaths occurred in India alone [1]. In 2005, the Government of India implemented Janani Suraksha Yojana (JSY), a nationwide program to increase the number of births occurring in health facilities. JSY improved the proportion of facility-based births amongst women of low socioeconomic status in rural areas [6], but had no impact on maternal mortality, largely because these rural primary health clinics (PHCs) lacked skilled birth attendants trained in evidence-based practices (EBP) [7]. Previous studies, such as the Community Level Interventions study for Preeclampsia (CLIP) in Karnataka have explored the capacity of healthcare providers to manage $\mathrm{PE} / \mathrm{E}$ in Indian primary care settings. CLIP found that, while nurses and community health workers were familiar with the clinical severity of $\mathrm{PE} / \mathrm{E}$, large knowledge gaps existed regarding disease etiology and medication route and dosage [8]. In Bihar, a poor and largely rural state in northeastern India, these challenges are likely more severe [9].

Simulation-based training has been shown to promote use of EBPs in emergency obstetric care in low-resource settings, though use of specific skills varied [10-13]. However, the impact of simulation training on use of EBPs for diagnosis and management of $\mathrm{PE} / \mathrm{E}$ in low-resource settings has not been reported. In order to be effective in this context, interventions must consider baseline knowledge and skills of providers $[14,15]$, as well as challenges inherent in magnesium sulfate and antihypertensive administration and continuous monitoring of maternal blood pressure (BP) $[16,17]$.

PRONTO International [18] developed a simulationbased training program to help address the need for provider training in emergency obstetric and neonatal care, including $\mathrm{PE} / \mathrm{E}$ diagnosis and management, in Bihar. Simulation training was embedded within AMANAT, a large-scale nurse mentoring program developed by CARE India [19] and the Government of Bihar, and implemented at 320 PHCs across Bihar between 2015 and 2017. This study aimed to assess the impact of simulationbased training on PE/E diagnosis and management in Bihar by evaluating changes in nurse mentees' use of EBPs in simulated $\mathrm{PE} / \mathrm{E}$ cases and exploring perceived barriers and enablers of high quality $\mathrm{PE} / \mathrm{E}$ care among nurse mentors.

\section{Methods}

\section{Study design}

This was a mixed methods study including quantitative and qualitative evaluations.

\section{Study setting}

Bihar has a population of over 100 million, of which $89 \%$ is rural [20]. The maternal mortality rate (MMR) is 208 per 100,000 live births in Bihar, compared to 167 per 100,000 for India as a whole. In Bihar, each PHC serves an average population of $\sim 190,000$ [20], and one nurse midwife is frequently responsible for all obstetric emergency and delivery care at a given $\mathrm{PHC}$.

\section{AMANAT training}

The AMANAT nurse mentoring program was implemented in Bihar over four phases between March 2015 and January 2017. Each eight-month phase included 80 PHCs. A total of 120 college-educated nurse mentors, recruited from across India, participated in the program. Mentors completed four weeks of training with CARE India prior to beginning the program, including one week focused on simulation facilitation and debriefing that was conducted by PRONTO International. This was followed by a four-day advanced simulation facilitation course four months later. Mentees were nurses working at PHCs who were qualified in either Auxiliary Nurse Midwifery (ANM) or General Nursing and Midwifery (GNM), requiring 18 months and 3 years of nursing training, respectively, following completion of secondary school. Six to eight nurses at each PHC were selected to participate in the AMANAT program. Across the four phases, a total of 3422 mentees were trained statewide. Through AMANAT, mentees received training in Basic Emergency Obstetric and Neonatal Care [21].

During each phase, 40 nurse mentors rotated in pairs between four PHCs, visiting each PHC for one week per month. During each visit, mentors facilitated simulations of emergency obstetric and neonatal care scenarios, all of which were video-recorded. Each simulation was followed by a video-guided debrief, led by the nurse mentor. During debriefs, mentees were encouraged to reflect on simulations and consider how to apply what they learned to clinical practice. The curriculum included a total of 31 simulation scenarios. During week four of each phase, mentees received training on the key aspects of $\mathrm{PE} / \mathrm{E}$ diagnosis and management through lectures, skills stations, and simulations. If time-permitted, mentors provided additional PE/E training during weeks five through eight.

\section{Part 1: Evaluating changes in nurse mentees' use of EBPs in simulated $\mathrm{PE} / \mathrm{E}$ cases}

We evaluated changes in nurse mentees' use of EBPs during simulated PE/E cases across all phases of the 
AMANAT program. The local PHC protocol for management of PE/E followed American College of Obstetricians and Gynecologists (2013) guidelines [22]. The expectation was that blood pressure (BP) be measured in all patients; if the BP was elevated (>140/90) or if the patient complained of headache, guidelines advised taking a targeted history, performing a physical exam, and checking urine protein. Preeclampsia with severe features was defined as BP > 140/90 and any of the following: proteinuria (1+ or greater), new onset cerebral or visual disturbances, severe right upper quadrant or epigastric pain unaccountable by other diagnoses, systolic BP $>160$, diastolic $\mathrm{BP}>110$. It is recommended that such patients be treated with a loading dose of magnesium sulfate (10 g IM and $4 \mathrm{~g}$ IV), an antihypertensive (usually nifedipine) if BP is in the severe range, targeting 130-140/100-90, and a foley catheter to monitor urine output. Next, depending on gestational age and stage of labor, the mother should be delivered in the clinic or referred to higher level of care. Eclamptic mothers require the same management with two additional steps, repositioning of mother to protect the airway onto her side and oxygen administration. PHCs in Bihar do not have the capacity to check protein/creatinine ratios, liver function tests, or platelet counts or preform cesarean deliveries. The PRONTO curriculum included two PE/E simulation scenarios, both of which involved a 17-year-old woman complaining of severe headache. If checked, mentees learned the patient had a BP of 170/112 with $3+$ (brisk) reflexes, $2+$ bilateral edema, and $3+$ urine protein. In the second scenario, the woman progressed to have an eclamptic seizure after a few minutes. Simulation videos were matched by scenario type (e.g., preeclampsia with severe features or eclampsia) and by facility. PHCs with two or more videos of the same scenario were included unless two videos occurred on the same day. If three videos were available, the first and last completed videos were selected for inclusion in the analysis.

EBP indicators were selected by clinical simulation experts from UCSF, PRONTO International, and CARE India. The indicators were used to develop a video analysis code window using Studiocode ${ }^{\text {tw }}$ software (Fig. 1). Simulation videos were coded by two Hindi-speaking nurses in Patna, Bihar. Any indicators deemed to represent simulation artifact were excluded from the analysis.

Binary indictors were categorized by subgroup (Table 1), with composite scores calculated for each subgroup. Two continuous indicators assessed key time intervals: 1) 'time from BP measurement to magnesium sulfate given,' 2) 'time from BP measurement to antihypertensive given.'

Sixteen videos (20.5\%) were randomly selected for double coding to assess inter-rater reliability across the two coders. Cohen's kappa was $>0.6$ for all binary variables [23] except epigastric pain $(k a p p a=0.59)$ and ICC
Table 1 Subgroups of binary indicators used to assess simulation videos

\begin{tabular}{ll}
\hline Subgroup & Scenario assessed \\
\hline 1) History questions (headache, blurry vision, & Both \\
epigastric pain, gestational age) & \\
2) Diagnostic tests [BP, heart rate (HR), fetal & Both \\
heart rate (FHR), clonus or deep tendon reflexes & \\
(DTR), edema, urine protein] & \\
3) Management steps (intravenous catheter placed, & Both \\
foley catheter inserted, magnesium sulfate given, & \\
antihypertensive given) & \\
4) Airway management steps (oxygen administered, Eclampsia only \\
patient repositioned laterally)
\end{tabular}

was $>0.9$ for both continuous variables [24], demonstrating strong inter-rater reliability.

\section{Statistical analysis}

The proportion of EBPs completed, subgroup composite scores, and key time intervals during mentees' first and last participation in $\mathrm{PE} / \mathrm{E}$ simulations were compared using generalized estimating equations (GEE) to appropriately estimate standard errors, adjusted for time (in days). All analyses were conducted in R Core Team, version 0.99 .903 [25].

\section{Part 2: Exploring perceived barriers and enablers of high quality $\mathrm{PE} / \mathrm{E}$ care among nurse mentors}

We explored barriers and enablers of high quality PE/E care through semi-structured interviews with current nurse mentors. Interviews were conducted in April 2017 in Patna. Interviewees were purposively selected, with preference given to mentors who had worked in different regions of Bihar as well as to those who had not previously participated in other interviews related to the AMANAT intervention. If both mentors working in a pair met these criteria, one was randomly selected for participation.

The interview guide employed open-ended questions and interviewers had flexibility to address emerging themes. Interviews were conducted by the first author and a Patna-based member of the PRONTO team. The Patna-based interviewer was fluent in Hindi and had qualitative research experience. All interviews were conducted in English. Interviews were held in private rooms at the PRONTO office or in private hotel rooms in Patna. Interview duration ranged from 42 to $66 \mathrm{~min}$.

\section{Thematic analysis}

Interviews were transcribed by the first author, with assistance from a transcription service in Bihar. To improve transcription quality, the first author listened to audio recordings and revised transcriptions as needed. Data were analyzed using the thematic content approach, consisting 


\begin{tabular}{|c|c|c|c|c|c|}
\hline ASSESSMENT & Physical Exam & \multirow{2}{*}{\multicolumn{2}{|c|}{$\begin{array}{l}\text { MANAGEMENT } \\
\text { Manuevers }\end{array}$}} & \multirow{2}{*}{\multicolumn{2}{|c|}{$\begin{array}{c}\text { Communication } \\
\text { Techniques }\end{array}$}} \\
\hline History & Checks Vital Signs & & & & \\
\hline Headache_1 & BP Assess_1 & \multicolumn{2}{|c|}{ IV Placed_1 } & \multicolumn{2}{|c|}{ SBAR_1 } \\
\hline Blurry vision_1 & Pulse Assess_1 Pulse Report_1 & \multicolumn{2}{|c|}{ Foley catheter inserted_1 } & \multicolumn{2}{|c|}{ Check back_1 } \\
\hline Epigastric pain_1 & FHR Report & \multicolumn{2}{|c|}{ Repositioned_1 } & \multirow{2}{*}{\multicolumn{2}{|c|}{ Call for help_1 }} \\
\hline & & \multicolumn{2}{|c|}{ Oxygen given_1 } & \multirow{2}{*}{\multicolumn{2}{|c|}{ Referral }} \\
\hline Asks decrease urination_1 & Exam & \multicolumn{2}{|c|}{ Airway suctioned_1 } & & \\
\hline Asks GA_1 & Check fundal height_1 & \multicolumn{2}{|c|}{ Medications } & \multirow{2}{*}{$\begin{array}{c}\text { Patient } \\
\text { delivered_1 }\end{array}$} & \multirow{2}{*}{$\begin{array}{c}\text { Patient } \\
\text { referred_1 }\end{array}$} \\
\hline Asks gravida_1 & Check mental status_1 & \multirow{3}{*}{$\begin{array}{c}\mathrm{MgSO} 4 \\
\text { ord_1 }\end{array}$} & $10 g \_1$ & & \\
\hline Asks baby moving & Check clonus_1 & & $49 \_1$ & \multicolumn{2}{|c|}{ Consultation with doctor_1 } \\
\hline normally_1 & Check DTR_1 & & Mg other_1 & \multirow{2}{*}{\multicolumn{2}{|c|}{$\begin{array}{c}\text { Communicate with referral } \\
\text { hospital_1 }\end{array}$}} \\
\hline Video Quality & Check oedema_1 & & & & \\
\hline Play video_1 & Vaginal Exam (Digital)_1 & \multirow{2}{*}{$\begin{array}{l}\text { AntiHTN } \\
\text { ord_1 }\end{array}$} & & \multirow{2}{*}{\multicolumn{2}{|c|}{$\begin{array}{l}\text { Communicate with patient } \\
\text { and family about condition/ } \\
\text { plan_1 }\end{array}$}} \\
\hline Problem seeing_1 & Urine protein test_1 & & $\frac{2.5 \mathrm{mg} .1}{\text { AntiHTN }}$ & & \\
\hline Unable to hear_1 & Verbalizes correct dx_1 & \multirow{2}{*}{\multicolumn{2}{|c|}{$\begin{array}{l}\text { Other med } \\
\text { ord_1 }\end{array}$}} & \multirow{2}{*}{\multicolumn{2}{|c|}{$\begin{array}{l}\text { Handed over referral } \\
\text { slip_1 }\end{array}$}} \\
\hline Coaching_1 & Seizure_1 & & & & \\
\hline
\end{tabular}

Fig. 1 Severe Preeclampsia and Eclampsia Clinical Coding Window

of four steps: 1) data familiarization, 2) identifying codes and themes, 3) developing a coding scheme and applying it to the data, and 4) organizing codes and themes [26, 27]. Two interviews were double coded. Any discrepancies were discussed and resolved to develop the final coding framework, which was applied to all remaining transcripts.

\section{Ethical considerations}

Written informed consent was obtained from all participants prior to the interview. Ethical approval was granted from the Committee on Human Research at the University of California San Francisco $(14-15,446)$ and the Institutional Review Board of the Indian Institute of Health Management Research.

\section{Results}

Part 1: Evaluating changes in nurse mentees' use of EBPs in simulated $\mathrm{PE} / \mathrm{E}$ cases

A total of 39 paired simulation videos were analyzed. Simulations averaged $10 \mathrm{~min}$ (range: $2-33 \mathrm{~min}$ ) and had a median of two participants each. The median duration between first and last participation in simulations was 62 days (range: $1-125$ days).

The proportion of simulated PE/E cases in which mentees completed key clinical indicators are displayed in Table 2. The proportion of simulations in which mentees 'asked about epigastric pain' increased from 43.6 to $51.3 \%$ $(p=0.03)$ and the proportion in which 'Foley catheter was inserted' trended upwards from 38.5 to $56.4 \%(p=0.06)$. The total number of 'history questions asked' increased from 1 to 2 ( $\mathrm{p}=0.03)$, and the total number of 'management steps completed' increased from 2 to $3(p=0.03)$.

Time required for nurse mentees to complete key management steps in simulated $\mathrm{PE} / \mathrm{E}$ cases is displayed in Table 3. Time from 'BP measured to magnesium sulfate given' remained relatively constant $(p=0.69)$, while time from 'BP measured to antihypertensive given' decreased by $3.1 \mathrm{~min}(p=0.06)$ between first and last participation in $\mathrm{PE} / \mathrm{E}$ simulations.

Part 2: Exploring perceived barriers and enablers of high quality $\mathrm{PE} / \mathrm{E}$ care among nurse mentors

Twelve nurse mentors, with a median age of 25.5 years, participated in interviews. Interviewees had worked as mentors for a median of 1.5 years. They came from eight different Indian states: Uttar Pradesh (3), Mumbai (2), Bombay (1), Kerala (2), Delhi (2), Chhattisgarh (1), West Bengal (1). Notably, no mentors were from Bihar.

We used the main themes emerging from the data to structure the presentation of material from the interviews, with themes broadly classified as barriers or enablers, as detailed below. 
Table 2 Proportion of simulated preeclampsia and eclampsia cases in which nurse mentees completed key history, diagnostic, and management steps ( $N=39$ matched pairs)

\begin{tabular}{|c|c|c|c|}
\hline History questions & $\begin{array}{l}\text { First simulation } \\
n(\%)^{\S}\end{array}$ & Last simulation & $p$-value \\
\hline Headache & $28(71.8)$ & $32(82.1)$ & $0.25^{\ddagger}$ \\
\hline Blurry vision & $17(43.6)$ & $20(51.3)$ & $0.49^{\ddagger}$ \\
\hline Epigastric pain & $1(2.6)$ & $7(17.9)$ & $0.01^{\ddagger}$ \\
\hline Asks gestational age & $8(20.5)$ & $12(30.8)$ & $0.14^{\ddagger}$ \\
\hline $\begin{array}{l}\text { Total steps completed } \\
\text { (median, IQR*) }\end{array}$ & $1.0(1.0-2.0)$ & $2.0(1.0-2.0)$ & $0.03^{\infty}$ \\
\hline \multicolumn{4}{|l|}{ Diagnostic tests } \\
\hline $\mathrm{BP}$ assessed & 39 (100.0) & $39(100.0)$ & NA \\
\hline FHR assessed & $29(74.4)$ & $30(76.9)$ & $0.08^{\ddagger}$ \\
\hline Fundal height measured & $3(7.7)$ & $7(17.9)$ & $0.15^{\ddagger}$ \\
\hline Clonus or DTR & $9(23.1)$ & $6(15.4)$ & $0.44^{\ddagger}$ \\
\hline Edema & $8(20.5)$ & $12(30.8)$ & $0.30^{\ddagger}$ \\
\hline Urine protein test & $12(30.8)$ & $11(28.2)$ & $0.80^{\ddagger}$ \\
\hline $\begin{array}{l}\text { Total steps completed } \\
\left(\text { median, IQR }{ }^{*}\right)\end{array}$ & $3.0(2.0-3.0)$ & $3.0(2.0-3.0)$ & $0.39^{\circ}$ \\
\hline \multicolumn{4}{|l|}{ Management steps } \\
\hline Magnesium sulfate given & $33(86.4)$ & $32(82.1)$ & $0.74^{\ddagger}$ \\
\hline Antihypertensive given & $22(56.4)$ & $28(71.8)$ & $0.20^{\ddagger}$ \\
\hline Intravenous catheter placed & $16(41.0)$ & $24(61.5)$ & $0.08^{\ddagger}$ \\
\hline Foley catheter inserted & $15(38.5)$ & $22(56.4)$ & $0.06^{\ddagger}$ \\
\hline $\begin{array}{l}\text { Total steps completed } \\
(\text { median, IQR*) }\end{array}$ & $2.0(1.5-3.0)$ & $3.0(2.0-4.0)$ & $0.03^{\infty}$ \\
\hline \multicolumn{4}{|c|}{ Airway management steps ( $N=13$ matched pairs $\left.{ }^{\wedge}\right)$} \\
\hline Oxygen given & $9(34.6)$ & $9(34.6)$ & NA \\
\hline Patient repositioned & $19(73.1)$ & $17(65.4)$ & $0.56^{\ddagger}$ \\
\hline $\begin{array}{l}\text { Total steps completed } \\
\text { (median, IQR*) }\end{array}$ & $1.0(0.25-2.0)$ & $1.0(0.25-1.75)$ & $0.71^{\infty}$ \\
\hline
\end{tabular}

${ }^{\S} n=$ Frequency of first and last simulated cases in which mentees completed key EBPs

$\%=$ Proportion of first and last simulated cases in which mentees completed key EBPs

* IQR = interquartile range of total number of steps completed

${ }^{\#}$ Difference in proportion of EBPs completed from first to last participation in simulated case

${ }^{\ddagger} \mathrm{GEE}$ logistic regression adjusted for duration (in days) between first and last simulations

${ }^{\infty} \mathrm{GEE}$ linear regression adjusted for duration (in days) between first and last simulations

^Airway management steps analyzed in simulated eclampsia cases only

\section{Barriers}

\section{Knowledge gaps}

Despite tremendous improvement, the majority of mentors noted that mentees struggled to understand diagnostic criteria of preeclampsia vs preeclampsia with severe features. Nurses had a hard time shifting from the previous categorization of mild and severe preeclampsia and, even though our training focused on the more recent criteria, many mentors themselves still referred to the older mild and severe categorization.

"They can do eclampsia and preeclampsia. But they're confusing like mild [preeclampsia without severe features] and severe .... sometimes previously I also confuse what I will do." (Age 26-30).

Confusion with diagnostic criteria was likely exacerbated by the fact that mentees at times had trouble assessing the quality of symptoms.

\section{"Epigastric [pain] they are not able to differentiate} with labor pain." (Age unknown).

Calculating the loading dose of magnesium sulfate, which required conversion of percentages to grams, was also very challenging for mentees.

"Mentees [with] ANM training, they don't know what is mg [milligram], so it's quite difficult." (Age 26-30).

Half of mentors acknowledged, however, that mentees were much more likely to treat preeclampsia with severe features with magnesium sulfate after the training, and only one said this was happening in her PHC prior to the training.

Additionally, half of mentors felt that mentees continued to have difficulty managing eclamptic seizures. They attributed this to fear and the low incidence of eclampsia.

\section{Interpersonal issues}

All mentors perceived the strict hierarchy between nurses and doctors as a significant barrier to high quality care. The majority also perceived that poor relationships between nurses and patients in PHCs were key barriers.

Table 3 Time to completion of key management steps by nurse mentees in simulated preeclampsia and eclampsia cases

\begin{tabular}{lllll}
\hline Time to completion of management steps & $n$ & First simulation & Last simulation & \\
\hline BP measured to magnesium sulfate given & 63 & $3.7(2.2-4.5)$ & $3.0(1.8-6.4)$ & 0.69 \\
BP measured to antihypertensive given & 47 & $5.8(2.6-9.7)$ & $2.6(1.0-6.6)$ & 0.06 \\
\hline
\end{tabular}

${ }^{\ddagger} \mathrm{GEE}$ linear regression adjusted for duration (in days) between first and last simulations 
"Yeah, they [nurses] are scared. If they tell something, also the doctor will say that, 'You know more than me, you're a doctor. You think that you are a doctor. You are not there to teach me."'

(Age 26-30).

The majority of mentors reported that aggressive behavior by family members of patients sometimes prevented nurses from providing evidence-based care. Nurse mentors were unsure of what led to this aggressive behavior, but they discussed fear, lack of education, previous medical mistreatment, and limited understanding of medical care as important factors.

"If anything happens, they're beating us." (Age 26-30).

"Actually, the thing is, more than the staff nurses, the patients' attendants [relatives] are more nervous. And because of their nervousness-the sisters [nurses] and doctors, they get nervous on top of that... So, it becomes a clash between them-and then the fight begins." (Age 26-30).

\section{Resource limitations}

All mentors agreed that human resource shortages, including doctors and nurses, were a key barrier. One to two nurses often covered the entire $\mathrm{PHC}$, including emergency care, vaccinations, and labor and delivery. Doctors were rarely present.

"So, twenty, for twenty patients, only one sister [nurse] is there to check blood pressure and take delivery. Often, it's very difficult ... so identification, early identification is not possible." (Age 26-30).

"Most of the times doctors are not available in the PHCs. They used to go for some meetings or some trainings ... Or they go to their private clinics." (Age 21-25).

Mentors felt that shortages of medications and urine protein strips were the most important supply-related barriers to high quality $\mathrm{PE} / \mathrm{E}$ care, and half described lack of ambulances as a key problem. The combination of ambulance shortages, costly private vehicles, and long distances between PHCs and referral hospitals made it nearly impossible to effectively refer patients who required a higher level of care. One mentor described how the lack of supplies in one PHC prevented adequate treatment of a woman with preeclampsia with severe features.
"I was scared ... Because now, mother, she is having [a] bad headache. [Elevated] blood pressure is there. No magnesium sulfate is there. No nifedipine is there... After one hour, she got eclampsia." (Age unknown).

The mother described above was subsequently transferred to a private clinic, where she delivered vaginally without receiving any medications to treat her condition. She recovered, but her baby died shortly after delivery.

\section{Enablers \\ Simulation training}

All mentors agreed that simulation training was an important enabler of high quality care. The majority felt that mentoring during live cases helped develop mentees' confidence, facilitating their ability to independently treat PE/E.

"Simulation is very important. And by doing simulation they will learn, they will remember that for lifetime. Because in theory [didactics] they will write and they will after some days they will forgot. By doing simulation they are remembering-yeah once I had this case and I manage like that." (Age 21-25).

\section{Communication between doctors and nurses}

Several mentors described how effective communication between doctors and nurses facilitated high quality care. Clinical discussions provided a formal setting to discuss complicated cases and review evidencebased care guidelines, fostering teamwork and increasing institutional support for mentees. Further, this platform allowed mentees to demonstrate their clinical proficiency, and some mentors believed this helped reduce hierarchical issues between doctors and nurses. Mentors also discussed the value of the two-challenge rule, a communication technique for respectfully asserting disagreement with superiors when there is a patient safety concern.

"Some mentees are doing [the] two challenge rule with doctors. 'We can't [only] give Lasix because we are not preventing the convulsions. And for the blood pressure, we have to give nifedipine." (Age 21-25).

\section{Physician leadership}

Mentors felt that doctor buy-in was critical to programmatic success. They described how AMANAT workshops helped doctors improve their skills in leadership and clinical care, particularly regarding accurate provision of intravenous magnesium sulfate. 
"In PHC, [the] medical officer will stay at home and, in many emergencies, they will call, just call ... but now they are coming, they are seeing, so mentees are having support now." (Age 21-25).

\section{Discussion}

To reduce maternal mortality in Bihar, it is essential that primary health providers are able to effectively diagnose and manage PE/E. We found that mentees had improved composite scores in 'history taking' and 'management steps;' however, only one individual EBP significantly improved from first to last participation in simulated $\mathrm{PE} / \mathrm{E}$ cases. The reason for this is likely multifactorial, encompassing need for additional training and resource limitations. For example, the low rates of urine protein assessment and oxygen administration in simulated cases may be partially attributed to actual supply shortages [28-30]. While the total number of 'management steps' completed by mentees increased, it is notable that magnesium sulfate administration did not improve. This finding is in contrast to previous evaluations of PE/E simulation training in high-resource settings [31, 32]. Nonetheless, the $76 \%$ rate of magnesium sulfate administration in simulated cases is much higher than that seen in the CLIP study, which found intravenous magnesium sulfate was never administered by nurses in PHCs [8]. This suggests that the initial simulation scenario may have overestimated mentees' baseline skills, particularly as they had likely already gained basic knowledge and skills through preceding lectures and skills stations. The inability of the simulation data to fully capture mentees improved skills was further supported by mentors' discussion of the impact of simulation learning on their mentees' clinical confidence and skills. For example, while mentors acknowledged that some mentees still called their mentors with questions regarding magnesium sulfate dosing and clarifying whether severe features were present or not, mentors shared many stories of mentees independently administering magnesium sulfate to mothers with preeclampsia with severe features. All but one mentor agreed that this would not have happened before training. These findings suggest that PE/E simulations may have an important role to play in improving diagnosis and management. Further studies should explore how $\mathrm{PE} / \mathrm{E}$ simulation training may translate into changes in clinical practice among providers.

This study found that knowledge gaps, resource limitations, and interpersonal-related issues were key barriers to high quality of $\mathrm{PE} / \mathrm{E}$ care in Bihar. Previous studies in India and meta-analyses from low-resource settings have also identified deficient supplies [16, 29], shortages of doctors and nurses [14], poor referral transport systems [14], and hierarchical issues among care providers [33, 34]. This study additionally identified aggressive behavior toward nurses by family members of patients, leading to fear of retaliation for negative health outcomes, as an additional barrier to provision of evidence-based, compassionate care in Bihar. This lack of therapeutic alliance at times could lead to catastrophic results for mothers. Mentors described situations in which providers would decide not to treat with magnesium or families would decline referral to a higher level of care, both of which are potentially life-saving practices. Future PRONTO interventions hope to address these challenges by including a unit on respectful maternity care that incorporates skills needed to manage family expectations.

Key enablers included simulation training, effective provider communication, and physician leadership. Other studies in low-resource settings have also identified participatory learning approaches [35], teamwork among doctors and nurses [3, 32, 36], and effective leadership [13] as facilitators of improved obstetric and emergency care. We found that communication techniques, such as the two-challenge rule, and clinical discussions can improve communication between providers, findings which are supported by results of related studies in high-resource settings [37, 38]. This suggests that team-based, inter-professional training can be successful in hierarchical cultures within Asia [39]. Finally, this study highlighted tailored workshops as an effective strategy to improve clinical and leadership skills among physicians, which in turn translated to higher motivation among mentees. This result parallels with studies from Kenya and South Africa that found that support from leadership was a key motivator for health workers and improved program success $[40,41]$.

This study has several limitations. Changes in mentees' use of EBPs were evaluated by comparing their first and last participation in simulated PE/E cases. As a result of this approach, different amounts of time elapsed between simulations for different facilities. However, changes in mentee performance were robust to adjustments for time. The first simulated scenario may not represent a true baseline for mentees' knowledge of $\mathrm{PE} / \mathrm{E}$, as the curriculum formally introduced preeclampsia in week 3 but mentees could have learned about it earlier if an affected patient had presented in week 1 or 2 . Further, mentors gave lectures and facilitated rapid reviews prior to the first simulation in order to maximize mentee learning during simulations. Interviewers were members of the PRONTO team who were involved in training mentors, which may have facilitated social desirability bias. To increase content validity, a local Hindi interviewer was present at all interviews and participants were ensured their responses were completely confidential in nature. The quantitative results on use of EBPs were based on simulated scenarios, and generalizability of these findings to actual clinical practice is unknown. 


\section{Conclusion}

Simulation training improved mentees' use of EBPs in simulated PE/E cases in Bihar, a key step to improving maternal survival. Knowledge gaps, resource limitations, and provider interpersonal issues were key barriers to $\mathrm{PE} / \mathrm{E}$ care in PHCs. Simulation training, effective communication, and physician leadership were key enablers. The next iteration of the training curriculum will incorporate lessons learned from these findings. Notably, addressing resource-related barriers requires both financial support and political will. An improved understanding of key barriers and enablers of high quality $\mathrm{PE} / \mathrm{E}$ care is an important initial step toward the design of contextually-targeted interventions to improve maternal survival in India.

\begin{abstract}
Abbreviations
ANM: Auxiliary Nurse Midwifery; BP: Blood pressure; CLIP: Community Level Interventions study for Preeclampsia; DTR: Deep tendon reflexes; EBP: Evidence-based practices; FHR: Fetal heart rate; GNM: General Nursing and Midwifery; JSY: Janani Suraksha Yojana; MMR: Maternal mortality rate; PE/ E: Preeclampsia and eclampsia; PHC: Primary health clinics
\end{abstract}

\section{Acknowledgements}

The authors would like to thank the video analysis team, including Praicey Thomas and Rohit Srivastava, for their tireless efforts in video data management and coding. Additionally, we would like to thank all of the nurse mentors and mentees for their tremendous work in promoting obstetric and neonatal care throughout Bihar. We also thank Dr. Hemant Shah, Indrajit Chaudhuri, Dr. Sridhar Srikantiah, Kingshuk Bagchi, and the CARE India management team for their leadership and engagement in the nurse mentoring project. Finally, we would like to thank the PRONTO International Master Trainers as well as Heidi Breeze-Harris, Jessica Dyer, and other PRONTO International Staff.

\section{Funding}

This study was funded by the Bill and Melinda Gates Foundation [grant number OPP1112431, 2015]. The funding body had no role in study design, data collection, analysis, interpretation, manuscript writing, or the decision to submit the manuscript for publication.

\section{Availability of data and materials}

Analyses are ongoing so the data is not yet publically available.

\section{Authors' contributions}

JR was involved in study design, data collection, and analysis, as well as manuscript drafting and revision. MM and AC helped with study design and were major contributors to the revision of the manuscript. AC also played a key role in curriculum and study design, supervision of nurse mentors, and video coding. MS and RG contributed greatly to qualitative and quantitative data analysis, respectively. HS was involved in study design, data management, and provided oversight of the video coding process. AG and TM helped with study design, program management, implementation, and manuscript revision. DW is the principal investigator and a major contributor to all aspects of this study and manuscript. All authors read and approved the final version of the manuscript.

\section{Ethics approval and consent to participate}

All participants in the simulation videos provided written consent for the use of video simulation data in aggregated analyses. All nurse mentors provided written consent prior to being interviewed. Ethics approval was granted from the institutional review boards of the University of California San Francisco $(14-15,446)$ and the Indian Institute of Health Management Research.

\section{Consent for publication}

Not applicable.

\section{Competing interests}

Dilys Walker and Susanna Cohen are founding members of PRONTO International and sit on its board of directors. None of the other authors have any conflicts of interest to declare.

\section{Publisher's Note}

Springer Nature remains neutral with regard to jurisdictional claims in published maps and institutional affiliations.

\section{Author details}

${ }^{1}$ Yale School of Medicine, Yale University, 333 Cedar St, New Haven, CT 06510, USA. ²Department of Pediatrics, University of California San Francisco, 550 16th Street, Box 1224, San Francisco, CA 94158, USA. ${ }^{3}$ Maternal, Adolescent, Reproductive, and Child Health Centre, London School of Hygiene and Tropical Medicine, London, UK. ${ }^{4}$ PRONTO International, State RMNCH+A Unit, C-16 Krishi Nagar, A.G. Colony, Patna, Bihar 80002, India. ${ }^{5}$ Institute for Global Health Sciences, University of California San Francisco, 550 16th Street, Box 1224, San Francisco, CA 94158, USA. ${ }^{6}$ CARE India, Bihar technical Support Program, 14, Patliputra Colony, Patna, Bihar 800013, India. ${ }^{7}$ Department of Obstetrics and Gynecology and Reproductive Services, University of California San Francisco, 1001 Potrero Ave, San Francisco, CA 94110, USA.

Received: 13 June 2018 Accepted: 9 January 2019 Published online: 23 January 2019

References

1. Kassebaum NJ, Barber RM, Bhutta ZA, Dandona L, Gething PW, Hay SI, et al. Global, regional, and national levels of maternal mortality, 1990-2015: a systematic analysis for the global burden of disease study 2015. Lancet. 2016 Oct 8;388(10053):1775-812.

2. Montgomery AL, Ram U, Kumar R, Jha P. Maternal mortality in India: causes and healthcare service use based on a nationally representative survey. PLoS One. 2014;9(1):e83331.

3. Duley L, Henderson-Smart DJ, Walker GJ, Chou D. Magnesium sulphate versus diazepam for eclampsia. Cochrane Database Syst Rev. 2010;12: CD000127.

4. Ameh C, Msuya S, Hofman J, Raven J, Mathai M, van den Broek N. Status of Emergency Obstetric Care in Six Developing Countries Five Years before the MDG Targets for Maternal and Newborn Health. Frasch MG, ed. PLoS ONE. 2012:7(12):e49938.

5. Harvey SA, Blandón YCW, McCaw-Binns A, Sandino I, Urbina L, Rodríguez C. Are skilled birth attendants really skilled? A measurement method, some disturbing results and a potential way forward. Bull World Health Organ. 2007 Oct;85(10):783-90.

6. Dehury RK, Samal J. Maternal health situation in Bihar and Madhya Pradesh: A comparative analysis of state fact sheets of National Family Health Survey (NFHS)-3 and 4. JCDR. 2016;10(9):IE01-4.

7. Randive $B$, Diwan $V$, De Costa A. India's conditional cash transfer programme (the JSY) to promote institutional birth: is there an association between institutional birth proportion and maternal mortality? PLoS One. 2013;8(6):e67452.

8. Ramadurg U, Vidler M, Charanthimath U, Katageri G, Bellad M, Mallapur A, et al. Community health worker knowledge and management of preeclampsia in rural Karnataka state. India Reprod Health. 2016;13(Suppl 2):113.

9. Oxford Poverty and Human Development Index Multidimensional Poverty Index 2016 Highlights South Asia. c2016. [cited 2017]. Available at http://www.ophi.org.uk/wp-content/uploads/MPI2016SOUTH-ASIA-HIGHLIGHTS_June.pdf.

10. Walton A, Kestler E, Dettinger JC, Zelek S, Holme F, Walker D. Impact of a low-technology simulation-based obstetric and newborn care training scheme on non-emergency delivery practices in Guatemala. Int I Gynaecol Obstet. 2016;132(3):359-64.

11. Evans $\mathrm{CL}$, Johnson $\mathrm{P}$, Bazant $\mathrm{E}$, Bhatnagar N, Zgambo J, Khamis $\mathrm{AR}$. Competency-based training "Helping Mothers Survive Bleeding after Birth" for providers from central and remote facilities in three countries." Int J Gynaecol Obstet 2014;126(3):286-290.

12. Nelissen E, Ersdal H, Ostergaard D, Mduma E, Broerse J, Evjen-Olsen B, et al. Helping mothers survive bleeding after birth: an evaluation of simulationbased training in a low-resource setting. Acta Obstet Gynecol Scand. 2014; 93(3):287-95. 
13. Das A, Nawal D, Singh MK, Karthick M, Pahwa P, Shah MB, et al. Impact of a nursing skill-improvement intervention on newborn-specific delivery practices: an experience from Bihar. India Birth. 2016;43(4):328-35.

14. Munabi-Babigumira S, Glenton C, Lewin S, Fretheim A, Nabudere H. Factors that influence the provision of intrapartum and postnatal care by skilled birth attendants in low- and middle-income countries: a qualitative evidence synthesis. Cochrane Database Syst Rev. 2017 Nov 17;2:CD011558.

15. Sheikh S, Qureshi RN, Khowaja AR, Salam R, Vidler M, Sawchuck D, et al. Health care provider knowledge and routine management of pre-eclampsia in Pakistan. Reprod Health. 2016;13(Suppl 2):104.

16. Hofmeyr J, Haws R, Bergstrom S, Lee AC, Okong P, Darmstadt GL, et al. Obstetric care in low-resource settings: what, who, and how to overcome challenges to scale up? Int J Gynaecol Obstet. 2009;107(Suppl 1):S21-45.

17. Aaserud M, Lewin S, Innvaer S, Paulesen EJ, Dahlgren AT, Trommald M, et al. Translating research into policy and practice in developing countries: a case study of magnesium sulphate for pre-eclampsia. BMC Health Serv Res. 2005;5:68.

18. PRONTO International. c2018. 2017. Available from: http://prontointernational.org.

19. CARE India. c2018. [cited 2018 Jan 1]. Available from: https://www.careindia.org.

20. Sharma, BP. Rural health statistics. Government of India Ministry of Health and Family Welfare Statistics Division 2015.

21. Vail B, Spindler H, Morgan MC, Cohen SR, Christmas A, Sah P, et al. Care of the mother-infant dyad: a novel approach to conducting and evaluating neonatal resuscitation simulation training in Bihar. India BMC Pregnancy Childbirth. 2017;17(1):252.

22. American College of Obstetricians and Gynecologists, Task Force on Hypertension in Pregnancy. Hypertension in Pregnancy. Obstet Gynecol. $2013 ; 122(5): 1122-1131$.

23. Green A. Kappa statistics for multiple raters using categorical classifications. San Diego, USA: Proceeds of the Twenty-Second Annual Conference of SAS Users Group; 1997

24. Kottner J, Audigé L, Brorson S, Donner A, Gajewski BJ, Hróbjartsson A, Roberts C, Shoukri M, Streiner DL. Guidelines for reporting reliability and agreement studies (GRRAS) were proposed. J Clin Epidemiol. 2011;64(1):96-106.

25. R Core Team (2016). R: A language and environment for statistical computing. R Foundation for Statistical Computing, Vienna, Austria. Version 1.0.143. c2009-2016. 2018. Available at: https://www.R-project.org/.

26. Pope C, Mays N. Qualitative research in health care. 2nd ed. London: BMJ Books; 2000.

27. Green J, Thorogood N. Qualitative methods for Health Research. 3rd ed. London: SAGE; 2014.

28. Jayanna K, Mony P, BM R, Thomas A, Gikwad A, Mohan HL, et al. Assessment of facility readiness and provider preparedness for dealing with postpartum haemorrhage and pre-eclampsia/eclampsia in public and private health facilities of northern Karnataka, India: a cross-sectional study. BMC Pregnancy Childbirth. 2014:14-304.

29. Chaturvedi S, Randive B, Mistry N. Availability of treatment for eclampsia in public health institutions in Maharashtra. India J Health Popul Nutr. 2013; 31(1):86-95.

30. Karvande S, Sonawane D, Chavan S, Mistry N. What does quality of care mean for maternal health providers from two vulnerable states of India? Case study of Bihar and Jharkhand. J Health Popul Nutr. 2016;35:6. https:// doi.org/10.1186/s41043-016-0043-3.

31. Daniels K, Arafeh J, Clark A, Waller S, Druzin M, Chueh J. Prospective randomized trial of simulation versus didactic teaching for obstetrical emergencies. Simul Healthc. 2010;5(1):40-5.

32. Ellis D, Crofts J, Hunt L, Read M, Fox R, James M. Hospital, simulation center, and teamwork training for eclampsia management: A randomized controlled trial. Obstet Gynecik. 2008;111(3):723-31.

33. Colvin J, Heer J, Winterton L, Winterton L, Mellenkamp M, Glenton C. A systematic review of qualitative evidence on barriers and facilitators to the implementation of task-shifting in midwifery services. Midwifery. 2013; 29(10):1211-21.

34. Akeju DO, Vidler M, Sotunsa JO, Osiberu MO, Orenuga EO, Olufemi OT, et al. Human resource constraints and the prospect of task-sharing among community health workers for the detection of early signs of pre-eclampsia in Ogun state. Niger Reprod Health. 2016;13(Suppl 2):111.

35. Lateef F. Simulation-based learning: just like the real thing. J Emerg Trauma Shock. 2010;3(4):348-52.

36. Kinney M, Smith J, Doherty T, Hermida J, Daniels K, Belizán J. Feasibility of community level interventions for pre-eclampsia: perspectives, knowledge, and task-sharing from Nigeria, Mozambique, Pakistan, and India. Reprod Health. 2016;13:125-9.

37. Wong AH, Gang M, Szyld D, Mahoney H. Marking an "attitude adjustment": using a simulation-enhanced Interprofessional education strategy to improve attitudes toward teamwork and communication. Simul Healthc. 2016;11(2):117-25

38. Sawyer T, Laubach VA, Hudak J, Yamamura K, Pocrnich A. Improvements in teamwork during neonatal resuscitaion after interprofessional TeamSTEPPS training. Neonatal Netw. 2013;32(1):26-33.

39. Shilkofski N, Hunt E. Identification of barriers to pediatric Care in LimitedResource Settings: A simulation study. Pediatrics. 2015;136(6):e1569-75.

40. Puoane T, Cuming K, Sanders D, Ashworth A. Why do some hospitals achieve better care of severely malnourished children than others? Five-year follow-up of rural hospitals in eastern cape. South Africa Health Policy Plan. 2008 Nov:34(6):428-37.

41. Mbindyo P, Gilson L, Blaauw D, English M. Contextual influences on health worker motivation in district hospitals in Kenya. Implement Sci. 2009:4:43.
Ready to submit your research? Choose BMC and benefit from:

- fast, convenient online submission

- thorough peer review by experienced researchers in your field

- rapid publication on acceptance

- support for research data, including large and complex data types

- gold Open Access which fosters wider collaboration and increased citations

- maximum visibility for your research: over $100 \mathrm{M}$ website views per year

At $\mathrm{BMC}$, research is always in progress.

Learn more biomedcentral.com/submissions 